\title{
Curvas de Progresso e Gradientes da Vassoura-de-Bruxa (Crinipellis perniciosa) em Cacaueiros Enxertados em Uruçuca, Bahia
}

\author{
Silvio A.M. Alves ${ }^{1}$, Alan W.V. Pomella ${ }^{2}$, William M. Aitken ${ }^{2}$ \\ \& Armando Bergamin Filho ${ }^{1}$
}

${ }^{1}$ Departamento de Entomologia, Fitopatologia e Zoologia Agrícola, ESALQ, Universidade de São Paulo, Cx. Postal 9 , CEP 13418-900, Piracicaba, SP, e-mail: silvio_alves@yahoo.com.br; ${ }^{2}$ Almirante Cacau Agrícola Comércio e Exportação LTDA, Cx. Postal 55, CEP 45630-000, Itajuípe, BA

(Aceito para publicação em 08/11/2006)

Autor para correspondência: Armando Bergamin Filho

ALVES, S.A.M., POMELLA, A.W.V. AITKEN, W.M. \& BERGAMIN FILHO, A. Curvas de progresso e gradientes da vassoura-de-bruxa (Crinipellis perniciosa) em cacaueiros enxertados em Uruçuca, Bahia. Fitopatologia Brasileira 31:483491. 2006.

\section{RESUMO}

A vassoura-de-bruxa tornou-se a mais importante doença do cacaueiro no Brasil desde a sua constatação no Estado da Bahia em 1989. O presente trabalho teve por objetivo estudar a curva de progresso e o gradiente da vassoura-de-bruxa, em plantio clonal, nas condições do sudeste da Bahia. O experimento foi conduzido em Uruçuca, BA, em área contendo cacaueiros enxertados com 16 genótipos diferentes e idade aproximada de três anos após a enxertia, no período de setembro de 2001 a julho de 2002. Mensalmente, foram quantificados os ramos e os frutos com sintoma da doença em três tratamentos: (1) poda fitossanitária semestral, (2) poda fitossanitária mensal e (3) poda fitossanitária mensal aliada à aplicação de fungicida mensal. O fungicida utilizado foi o óxido cuproso na dose de $3 \mathrm{~g}$ do i.a./planta/aplicação. A fonte de inóculo utilizada foi um plantio adjacente com alta incidência da doença. Na análise temporal, foram ajustadas curvas de crescimento e calculados os coeficientes de determinação e as taxas de progresso da incidência. Houve bom ajuste dos dados de progresso da doença em vassouras vegetativas e em frutos ao modelo monomolecular. A incidência final de doença em vassouras vegetativas e em frutos no tratamento com poda fitossanitária e fungicida foi aproximadamente cinco vezes menor do que nos outros tratamentos. $\mathrm{Na}$ análise espacial, os resultados não evidenciaram a presença de gradiente de doença. Com base nos resultados ficou evidenciado que a integração dos métodos cultural, químico e genético resultou em menor taxa de progresso da doença e mais baixa incidência final.

Palavras-chave adicionais: Theobroma cacao, relação hospedeiro-patógeno, resistência genética, disseminação, manejo integrado.

\begin{abstract}
Disease progress curves and gradients of witches' broom disease in a cloned cocoa area, in Uruçuca, Bahia

Witches' broom has been considered the most important cocoa disease in Brazil since its first outbreak in Bahia in 1989. The objective of this work was to evaluate the disease progress curve and the gradient of witches' broom based on symptoms on flushes and pods of cocoa. The experiment was carried out in Uruçuca, southeast of Bahia State, in an area of grafted cocoa trees with 16 different genotypes, at an age of approximately three years after grafting, from September 2001 to July 2002. Assessments of symptomatic branches and pods were done monthly. Three treatments were used: (i) phytosanitation at sixmonthly interval, (ii) monthly phytosanitation and (iii) monthly phytosanitation plus monthly fungicide application (cuprous oxide at a dose of $3 \mathrm{~g}$ of a.i./plant/application). An adjacent area with abandoned cocoa trees showing high disease incidence was considered the main source of inoculum. In the temporal analysis, the monomolecular growth model was fitted to data and disease progress rates and determination coefficients were compared. A good fit for vegetative brooms and diseased pods was obtained with the monomolecular model. The final disease incidence in vegetative brooms and pods in the treatment that included the fungicide application was approximately five times lower than in the other treatments. Spatial analysis showed no evidence for a disease gradient. These results showed that the integration of cultural, chemical and genetic control methods allows a slower disease progress and lower final incidence of the disease.
\end{abstract}

Additional keywords: Theobroma cacao, Crinipellis perniciosa, host-pathogen relationships, genetic resistance, dissemination, integrated management.

\section{INTRODUÇÃO}

Na safra 1984/85 o Brasil foi o segundo maior produtor mundial de cacau, produzindo aproximadamente

*Parte da Dissertação de Mestrado do primeiro autor. ESALQ, Universidade de São Paulo. 2003.
400.000 toneladas. Em 2000, porém, a produção caiu para 210.000 toneladas (FAO, 2002). Como conseqüência dessa queda progressiva, já a partir de 1997, o Brasil, de exportador, passou a importar o produto. No ano de 2000 foram importadas cerca de 71.000 toneladas de amêndoas de cacau (Companhia das Docas do Estado da Bahia, 2002).

A queda da produção nacional nos últimos anos pode 
ser explicada, em grande parte, pela introdução do patógeno causador da vassoura-de-bruxa do cacaueiro (Crinipellis perniciosa (Stahel) Singer) no Estado da Bahia, em 1989 (Pereira et al., 1990). A Bahia é responsável por mais de $80 \%$ da produção nacional de cacau.

A maior limitação à produção de cacau no Brasil é causada pelas doenças fúngicas e, dentre elas, a vassourade-bruxa se destaca como a mais importante (Luz et $a l .$, 1997). Os danos à produção de cacau no Estado da Bahia, devidos à vassoura-de-bruxa, foram estimados em aproximadamente 105 mil toneladas nas safras 1995/96 e 1996/97 (Santos Filho et al., 1998).

Além de impactos econômicos diretos resultantes da menor produção de cacau, outras mudanças ocorreram na região produtora da Bahia, como alteração no uso da terra, venda de propriedades, nível de emprego e danos ao meio ambiente (Trevizan, 1996).

Atualmente, uma das recomendações da Comissão Executiva do Plano da Lavoura Cacaueira (CEPLAC) para a reabilitação de plantas suscetíveis à vassoura-debruxa é o uso de variedades clonais resistentes, por meio da enxertia (Rosa, 1998). Porém, devido ao alto custo de renovação das plantações, é comum ocorrer áreas abandonadas próximas a áreas enxertadas. Na Bahia, o cacaueiro é explorado de maneira diferente da região amazônica, seu habitat natural. Os plantios são mais densos e contínuos entre as propriedades agrícolas. Purdy \& Schmidt (1996) consideram que em condições de plantio a epidemiologia da doença é diferente, pois há aumento de tecidos suscetíveis, estes muitas vezes são sincronizados entre as plantas, e o microclima proporcionado pela plantação favorece a infecção e esporulação do agente causal.

Um projeto internacional, iniciado em 1985, realizou estudos epidemiológicos no Brasil e em outros países da América do Sul. No Brasil, os experimentos foram conduzidos na região amazônica, pois a vassoura-de-bruxa ainda não havia sido constatada na Bahia (Rudgard et al., 1993). Assim, com base nas peculiaridades da cultura do cacaueiro na região baiana, principalmente quanto ao clima e ao uso de materiais com diferentes níveis de resistência, é de se esperar que a doença apresente um novo comportamento.

As características do patossistema Crinipellis perniciosa-cacau podem ser estudadas por meio do uso de ferramentas epidemiológicas, como o estudo de curvas de progresso de doença e curvas de gradiente de doença (Evans \& Solorzano, 1982; Cifuentes et al., 1982; Aragundi et al., 1987; Rugdard, 1987; Maddison et al., 1993). Considerando a necessidade de conhecimentos epidemiológicos nas condições do sudeste baiano, o objetivo deste trabalho foi estudar a influência de fonte de inóculo externa sobre área de plantio clonal, esta submetida a diferentes medidas de controle (cultural e químico), por meio de análises de gradiente e curvas de progresso da vassoura-de-bruxa em ramos e frutos.

\section{MATERIAL E MÉTODOS}

\section{Área experimental}

O experimento foi conduzido na Fazenda Novo Oriente, localizada no município de Uruçura, Bahia. A área experimental apresentava topografia plana a ligeiramente ondulada, onde foram demarcadas três sub-áreas experimentais retangulares de 15 por $460 \mathrm{~m}$ intercaladas por duas faixas de 10 por $460 \mathrm{~m}$, usadas como bordadura. Cada sub-área da área experimental foi submetida a um tratamento diferente (Figura 1): sub-área 1 - poda fitossanitária semestral (tratamento 1); sub-área 2 - poda fitossanitária mensal (tratamento 2); sub-área 3 - poda fitossanitária mensal aliada à aplicação mensal de fungicida (tratamento 3). O fungicida utilizado foi o óxido cuproso na dose de $3 \mathrm{~g}$ do i.a./planta/ aplicação. $\mathrm{O}$ entorno da área experimental consistia em: área de cacaueiro abandonado (considerada a fonte de inóculo), mata secundária, um riacho seguido de pastagem e área de cacaueiro enxertado com genótipos resistentes (Figura 1).

\begin{tabular}{|c|c|c|c|}
\hline \multirow{7}{*}{ 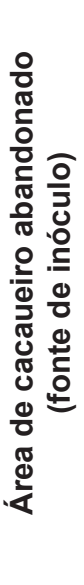 } & Floresta com mata secundária & \multirow{7}{*}{ 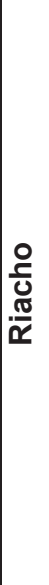 } & \multirow{7}{*}{ 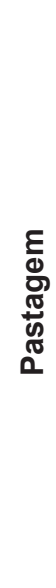 } \\
\hline & Sub-área 1 (15 m x 460 m) & & \\
\hline & Bordadura (10 m x $460 \mathrm{~m})$ & & \\
\hline & Sub-área 2 (15 m x 460 m) & & \\
\hline & Bordadura (10 m x $460 \mathrm{~m})$ & & \\
\hline & Sub-área 3 (15 m x 460 m) & & \\
\hline & $\begin{array}{l}\text { Área de cacaueiro enxertado com } \\
\text { genótipos resistentes }\end{array}$ & & \\
\hline
\end{tabular}

FIG. 1 - Croqui da área experimental e seus limites. Sub-área 1 (tratamento1): poda fitossanitária semestral; sub-área 2 (tratamento 2): poda fitossanitária mensal; sub-área 3 (tratamento 3): poda fitossanitária mensal aliada à aplicação mensal de óxido cuproso.

A área experimental possuía 16 genótipos diferentes, distribuídosaleatoriamente, enxertados sobrecacaueirosadultos. Esses genótipos foram resultantes de seleção feita na própria fazenda, baseada na menor incidência da doença observada. As plantas possuíam identificação em placa metálica, com informações como a data da enxertia (mês e ano) e o genótipo enxertado (sigla composta das letras "NO", seguida de dois números). $\mathrm{O}$ sombreamento na área foi estimado em cerca de $50 \%$, proporcionado por árvores nativas da Mata Atlântica, sistema de cultivo conhecido como cabruca. A mesma foi submetida a contínuo controle de plantas daninhas, por meio de roçagens.

\section{Obtenção dos dados}

No mês de abril de 2001, a área experimental foi 
demarcada e todas as flores e frutos foram removidos da mesma, para que o experimento não sofresse interferência de práticas anteriores. Os dados obtidos entre os meses de setembro de 2001 e fevereiro de 2002 foram considerados como pertencentes à safra principal e aqueles resultantes das colheitas nos meses de março a agosto de 2002 foram considerados como os da safra temporã (Carzola et al., 1989). A soma das colheitas da safra principal e temporã foi denominada como safra global.

Em cada inspeção foram quantificados os ramos doentes e os frutos maduros; estes foram classificados como: sadios, com vassoura ou com outros danos. Os frutos com vassoura apresentavam sintomas típicos, como lesões necróticas externas acompanhadas de necrose nas amêndoas. Os frutos classificados como outros danos foram aqueles que sofreram ataque de pássaros, roedores ou outros patógenos. Não foram quantificados os frutos produzidos nos porta-enxertos e nem aqueles que não vingaram em virtude de distúrbios de natureza fisiológica. Todos os frutos colhidos foram quebrados no próprio campo e todas as cascas foram retiradas da área para evitar a presença de uma fonte de inóculo no interior da área experimental.

Os dados foram observados nas plantas que possuíam a identificação do material enxertado e data de enxertia nos anos de 1998 e 1999. Para fins de estudo de gradiente de doença, as plantas foram demarcadas em seções transversais de $10 \mathrm{~m}$ a partir da fonte de inóculo (a área de cacaueiro abandonada, Figura 1), como utilizado no trabalho de Maddison et al. (1993).

\section{Curvas de progresso da doença}

Dos 16 genótipos presentes na área experimental, dez se repetiam nas três sub-áreas (Tabela 1), os quais foram utilizados nas análises de progresso temporal da doença.

O cálculo da proporção de doença foi baseado

TABELA 1 - Número de plantas de cada genótipo de cacaueiro em três sub-áreas de cultivo para estudos de gradiente de doença, fazenda Novo Oriente, Uruçuca, Bahia, 2001/02

\begin{tabular}{cccc}
\hline \multirow{2}{*}{ Genótipos } & \multicolumn{3}{c}{ Sub-áreas } \\
\cline { 2 - 4 } & 1 & 2 & 3 \\
\hline NO-02 & 36 & 7 & 3 \\
NO-10 & 9 & 36 & 17 \\
NO-12 & 40 & 12 & 6 \\
NO-13 & 6 & 10 & 8 \\
NO-17 & 20 & 22 & 21 \\
NO-24 & 32 & 33 & 14 \\
NO-34 & 64 & 44 & 33 \\
NO-42 & 43 & 61 & 28 \\
NO-50 & 12 & 13 & 10 \\
NO-52 & 10 & 12 & 14 \\
NO-56 & 6 & - & - \\
NO-63 & - & 29 & - \\
NO-22 & - & - & 5 \\
NO-36 & - & - & 18 \\
NO-38 & - & - & 21 \\
NO-53 & - & - & 83 \\
Total & 278 & 279 & 281 \\
\hline
\end{tabular}

nos valores médios de incidência da doença por planta. A proporção de doença em cada avaliação foi obtida realizando-se a divisão entre a média da avaliação e a maior média acumulada.

Foram realizados ajustes para a contagem de vassouras vegetativas, no período de setembro de 2001 a julho de 2002, para as três sub-áreas. A mesma metodologia foi utilizada para a contagem de frutos com vassoura, no período de setembro de 2001 a janeiro de 2002 , ou seja, na safra principal. $\mathrm{O}$ modelo ajustado foi o monomolecular, dado pela fórmula $Y=1-\left(1-Y_{0}\right) * \exp \left(-r_{\mathrm{M}} t\right)$, onde $Y$ é a proporção de doença, $Y_{0}$, a proporção de doença no tempo 0 , $t$, o tempo em meses e $r_{\mathrm{M}}$ a taxa monomolecular de progresso da doença. $\mathrm{O}$ grau de ajuste do modelo foi determinado em função dos valores do coeficiente de determinação $\left(R^{2}\right)$. O progresso da doença nas sub-áreas foi comparado por meio dos valores das taxas de progresso $\left(r_{\mathrm{M}}\right)$. Para o cálculo de $r_{\mathrm{M}}$, os dados de proporção de doença $(Y)$ foram transformados utilizando-se Monito $[Y=\ln (1 /(1-Y))]$; em seguida, as taxas foram calculadas por meio da regressão linear dos dados transformados em função do tempo.

\section{Gradientes da doença}

Fonte de inóculo. Foi considerada a área adjacente à experimental com cacaueiros da variedade comum, safreiros, abandonados e com alta incidência da doença (Figura 1). Nos meses de abril de 2001 e junho de 2002 realizaram-se contagens do número de vassouras vegetativas para quantificar o potencial de inóculo nessa área. Foram contadas todas as vassouras verdes e secas de quinze plantas escolhidas aleatoriamente. A contagem de frutos doentes não foi considerada devido ao alto índice de frutos secos $\mathrm{e}$ atacados por roedores, fato que inviabilizou o diagnóstico da doença nesses frutos.

Análise dos dados. As curvas de gradiente de doença foram obtidas usando-se os dados de todos os genótipos em conjunto e separadamente para os quatro mais abundantes. $\mathrm{Na}$ análise conjunta foram utilizadas: 278 plantas na subárea 1, 279 plantas na sub-área 2 e 281 plantas na sub-área 3. Os quatro genótipos mais abundantes foram: NO-17, NO24 , NO-34 e NO-42. O número de plantas de cada um desses genótipos em cada sub-área são apresentados na Tabela 1. Foram ajustadas curvas de gradiente de doença para cada safra utilizando-se dois modelos empíricos, conhecidos como lei da potência $\left[y_{P}(x)=a_{P} x^{b P}\right]$ e lei exponencial $\left[y_{E}(x)=a_{E} \exp \left(-b_{E} x\right)\right]$, onde $y$ representa a doença, $x$ a distância da fonte de inóculo e $a$ e $b$ são parâmetros; os subscritos $P$ e $E$ referem-se à lei da potência e à lei exponencial, respectivamente (Bergamin Filho et al., 2002).

$\mathrm{Na}$ análise foi considerado o somatório de ramos e frutos doentes no período de cada safra. Foi calculada a média da incidência da doença a cada $10 \mathrm{~m}$ da seção de $460 \mathrm{~m}$ a partir da fonte de inóculo, perfazendo um total médio de 46 observações. Após o cálculo da análise de variância, o coeficiente angular e o coeficiente de determinação foram comparados. 


\section{RESULTADOS}

\section{Curvas de progresso da doença}

As curvas de progresso da doença determinadas em vassouras vegetativas (Figura 2A) evidenciaram uma menor taxa de progresso no tratamento 3. A proporção final de doença observada, nesse tratamento, foi cerca de $20 \%$ do valor observado no tratamento 1 . O mesmo ocorreu para os frutos (Figura 2B). No tratamento 3, a proporção final de doença foi cerca de $22 \%$ do observado no tratamento 2 . As curvas dos tratamentos 2 e 1 foram semelhantes, embora a taxa de progresso da doença no tratamento 2 tenha sido superior àquela observada no tratamento 1 (Tabela 2).

Houve bom ajuste dos dados de vassouras em ramos $\left(R^{2}\right.$ entre 0,837 e 0,961$)$ e em frutos $\left(R^{2}\right.$ entre 0,909 e 0,974$)$ ao modelo monomolecular (Tabela 2). O tratamento 3 apresentou menores taxas de progresso da doença, tanto em ramos como em frutos (Tabela 2).

\section{Gradientes da doença}

Fonte de inóculo. A estimativa do potencial de inóculo na área abandonada revelou, em abril de 2001, a severidade média de 82,0 vassouras vegetativas por planta (62,3 secas e 19,7 verdes). Na segunda avaliação (junho de 2002) a severidade média por planta foi de 104,0 vassouras, sendo 102,4 secas e 1,6 verdes. A diferença no número de vassouras verdes nos dois períodos avaliados pode ser explicada pelo grande número de lançamentos vegetativos nos meses de fevereiro e março de 2001, período precedente à primeira avaliação, fato não observado em abril e maio de 2002, período precedente à segunda avaliação. $\mathrm{O}$ desvio padrão da média foi de aproximadamente 44 unidades. Nas plantas amostradas, foi raro encontrar ramos sadios. As plantas de maior porte (com maior número de ramos) apresentaram maior quantidade de vassouras. A escolha aleatória das plantas independentemente do tamanho pode explicar a alta variação observada.

Incidência em ramos. A lei exponencial foi utilizada em todas as análises por ter apresentado maior número de variâncias significativas, quando comparada à lei da potência.
Das 120 regressões realizadas, 13 foram significativas pela lei exponencial e oito foram significativas pela lei da potência (dados não apresentados). Na safra principal foi evidenciada a formação de gradiente para alguns genótipos analisados separadamente, porém com baixos coeficientes de determinação (Tabela 3 e Figura 3). Na safra temporã, as análises não foram significativas, indicando a ausência de gradiente (Tabela 3). Os valores de inclinação obtidos revelaram pequena taxa de diminuição da incidência com o aumento da distância da fonte de inóculo.

A ausência de gradiente também foi observada para a maioria das regressões realizadas nos quatro genótipos mais abundantes, nas duas safras (Tabela 3). De forma geral, a safra temporã apresentou menor incidência da doença, comparada à safra principal. Apenas os genótipos NO-17 (na sub-área 1), NO-24 (na sub-área 2), na safra principal, e o genótipo NO-17 (na sub-área 2), na safra temporã, apresentaram gradiente significativo (Tabela 3 ).

Incidência em frutos. A análise conjunta das incidências em frutos nas plantas das três sub-áreas não revelou de forma conclusiva a presença de gradiente de doença (Tabela 4). Embora tenha sido significativa a análise de variância na sub-área 1, na safra principal, e nas subáreas 2 e 3 , na safra temporã, os valores dos coeficientes de determinação foram baixos (Tabela 4). Ademais, o coeficiente angular na sub-área 1, safra principal, foi positivo. O baixo ajuste da reta aos dados foi devido à grande variação nos níveis de incidência em todas as distâncias avaliadas (Figura 4).

$\mathrm{Na}$ safra principal, somente o genótipo NO-24 (na sub-área 1) apresentou gradiente significativo. Na safra temporã, apenas os genótipos NO-34 (na sub-área 2) e NO42 (na sub-área 3) apresentaram gradiente de incidência significativo (Tabela 4).

\section{DISCUSSÃO}

\section{Curvas de progresso da doença}

Andebrhan (1985), ao avaliar o progresso da vassourade-bruxa em três localidades na Amazônia, verificou que

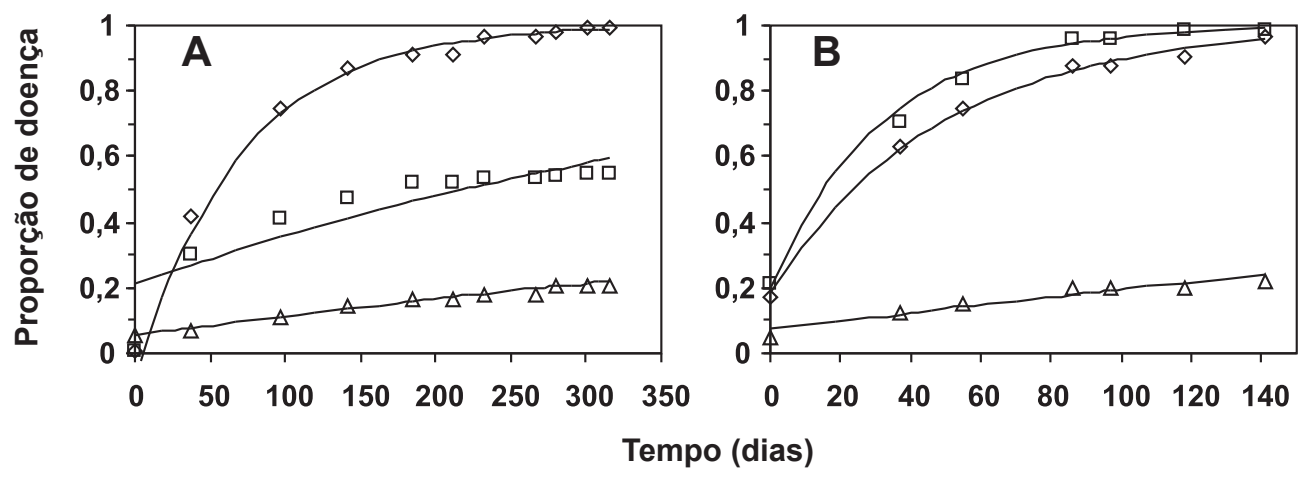

FIG. 2 - A. Curvas de progresso da incidência vassoura-de-bruxa do cacaueiro em vassouras vegetativas, na safra global; B. frutos com vassoura, na safra principal, nos tratamentos 1 (poda fitossanitária semestral - losangos), 2 (poda fitossanitária mensal - quadrados) e 3 (poda fitossanitária mensal e tratamento químico mensal - triângulos). Ajuste epidemiológico do modelo monomolecular (linha contínua). Dia 0 corresponde a 11/09/2001. 
TABELA 2 - Taxas de infecção médias $\left(r_{\mathrm{M}}\right)$ e coeficientes de determinação $\left(R^{2}\right)$ do progresso da vassoura-de-bruxa do cacaueiro em diferentes tratamentos $(1$ = poda fitossanitária semestral; 2 = poda fitossanitária mensal; 3 = poda fitossanitária mensal e tratamento químico mensal), de acordo com o modelo monomolecular

\begin{tabular}{cccc}
\hline \hline Órgão & Tratamentos & $\boldsymbol{R}^{\mathbf{2}}$ & $\boldsymbol{r}_{\mathbf{M}}$ \\
\hline Ramos & 1 & 0,961 & 0,405 \\
& 2 & 0,837 & 0,087 \\
& 3 & 0,973 & 0,021 \\
Frutos & 1 & 0,974 & 0,624 \\
& 2 & 0,969 & 0,936 \\
& 3 & 0,909 & 0,042 \\
\hline
\end{tabular}

${ }^{1}$ por mês.

uma única poda fitossanitária na estação seca do ano não impediu o progresso da doença através de novas infecções. O ritmo de crescimento do cacaueiro é dependente do genótipo, condição edafo-climática e manejo (Andebrhan \& Almeida, 1985). Na Bahia, normalmente o maior pico de lançamento foliar ocorre entre setembro e novembro (Alvim, 1977; Carzola et al., 1989), mesma época em que um maior número de sintomas em ramos foi observado neste trabalho (Figura 2).

As taxas mensais de progresso da doença encontradas por Andebrhan (1985) em Benevides, Pará, nos anos de 1980 a 1982 , foram de 0,76 a 0,96 para vassouras vegetativas, 0,71 a 0,87 para almofadas florais e 0,53 a 0,70 para frutos com vassoura. Os valores obtidos no presente trabalho em vassouras vegetativas, nos tratamentos 1 e 2 , foram menores do que os obtidos em Benevides. Essas menores taxas podem ter sido ocasionadas por diferenças na resistência dos materiais, pela maior freqüência na realização da poda, ou ainda, por diferenças climáticas entre as regiões. As taxas de progresso da doença em frutos nos tratamentos 1 e 2 foram similares àqueles observados em Benevides, indicando que as resistências dos materiais podem ser semelhantes para esse órgão.

Embora tenham sido realizadas apenas duas remoções de vassouras vegetativas por ano na sub-área 1, não foi observada a produção de basidiocarpos nas vassouras na ocasião da remoção, sendo, portanto, as infecções em frutos e ramos atribuídas a inóculo vindo de fora da área experimental. O período de incubação da vassoura-debruxa na Bahia é em média de quatro semanas. Porém, pode ocorrer infecção latente em gemas vegetativas dormentes, que se desenvolvem quando a planta reinicia a brotação (Luz et al., 1997). A constatação de sincronismo entre o maior lançamento vegetativo e sintomas da doença resultou no crescimento monomolecular da mesma. Esse é um indício de se tratar de uma doença com período de incubação dependente da fenologia do hospedeiro (Bergamin Filho \& Amorim, 2002).

O tratamento que combinou os métodos cultural, químico e genético proporcionou considerável redução na taxa de progresso da doença, o que demonstra o potencial da aplicação do manejo integrado para a vassoura-de-bruxa no sudeste baiano (Figura 2 e Tabela 2).

\section{Gradiente de doença}

Fonte de inóculo. Os resultados obtidos na área considerada como fonte de inóculo estão de acordo com aqueles obtidos em outras regiões com plantas suscetíveis. Cifuentes et al. (1982) encontraram incidências de aproximadamente 42,5 vassouras por planta na variedade

TABELA 3 - Resultado das análises de regressão das contagens de vassoura vegetativa em função da distância da fonte de inóculo, na safra principal e temporã, aplicando o modelo exponencial, em genótipos de cacaueiro

\begin{tabular}{|c|c|c|c|c|c|c|c|c|c|c|c|}
\hline \multirow{3}{*}{ Genótipo } & \multirow{3}{*}{$\begin{array}{l}\text { Sub- } \\
\text { área }\end{array}$} & \multicolumn{10}{|c|}{ Safra } \\
\hline & & \multicolumn{5}{|c|}{ Principal } & \multicolumn{5}{|c|}{ Temporã } \\
\hline & & $\begin{array}{l}\text { Inclinação } \\
\text { (b) }\end{array}$ & $\begin{array}{c}\text { Interseção } \\
\text { (In a) }\end{array}$ & $R^{2}$ & $F^{1}$ & & $\begin{array}{l}\text { Inclinação } \\
\text { (b) }\end{array}$ & $\begin{array}{c}\text { Interseção } \\
(\ln \text { a) }\end{array}$ & $R^{2}$ & $F^{1}$ & \\
\hline \multirow[t]{3}{*}{ Todos } & 1 & $-0,0008$ & 0,6278 & 0,088 & 4,23 & $*$ & 0,0003 & 0,0455 & 0,059 & 2,74 & ns \\
\hline & 2 & $-0,001$ & 0,5209 & 0,228 & 12,96 & $* *$ & $-0,0003$ & 0,1141 & 0,080 & 3,82 & $\mathrm{~ns}$ \\
\hline & 3 & $-0,0004$ & 0,1778 & 0,124 & 6,21 & $*$ & $-0,0001$ & 0,0754 & 0,022 & 1,01 & ns \\
\hline \multirow[t]{3}{*}{ NO-17 } & 1 & $-0,0038$ & 1,3811 & 0,763 & 25,72 & $* *$ & 0,0002 & 0,0349 & 0,015 & 0,12 & ns \\
\hline & 2 & $-0,0015$ & 0,3989 & 0,306 & 2,20 & ns & $-0,0023$ & 0,5935 & 0,591 & 7,22 & $*$ \\
\hline & 3 & $-0,0004$ & 0,1573 & 0,120 & 1,36 & ns & $-8.10^{-5}$ & 0,055 & 0,006 & 0,06 & ns \\
\hline \multirow[t]{3}{*}{ NO-24 } & 1 & $-0,0021$ & 0,8514 & 0,265 & 4,32 & ns & $-0,0002$ & 0,0989 & 0,115 & 1,55 & ns \\
\hline & 2 & $-0,002$ & 0,7468 & 0,667 & 24,05 & $* *$ & $-0,0001$ & 0,0538 & 0,128 & 1,77 & ns \\
\hline & 3 & 0,0008 & 0,0642 & 0,027 & 0,17 & ns & $-0,0011$ & 0,1354 & 0,027 & 0,17 & ns \\
\hline \multirow[t]{3}{*}{ NO-34 } & 1 & $-0,0006$ & 0,3582 & 0,058 & 1,91 & ns & 0,0001 & 0,0148 & 0,019 & 0,59 & ns \\
\hline & 2 & $-0,0012$ & 0,2964 & 0,212 & 3,77 & ns & $-2.10^{-5}$ & 0,0285 & 0,000 & 0,01 & ns \\
\hline & 3 & 0,0001 & $-0,006$ & 0,042 & 0,66 & ns & 0,0002 & $-0,0109$ & 0,042 & 0,66 & ns \\
\hline \multirow[t]{3}{*}{ NO-42 } & 1 & $-0,0021$ & 0,5563 & 0,161 & 2,11 & ns & $-0,0005$ & 0,0928 & 0,144 & 1,86 & ns \\
\hline & 2 & $-0,0001$ & 0,2194 & 0,006 & 0,15 & ns & $-0,0001$ & 0,0691 & 0,038 & 1,04 & ns \\
\hline & 3 & $-0,0014$ & 0,2237 & 0,072 & 0,85 & ns & 0,0018 & $-0,0731$ & 0,133 & 1,69 & ns \\
\hline
\end{tabular}

$1 *$,** significante a $5 \%$ e a $1 \%$ de probabilidade, respectivamente; ns, não significativo. 
Safra principal

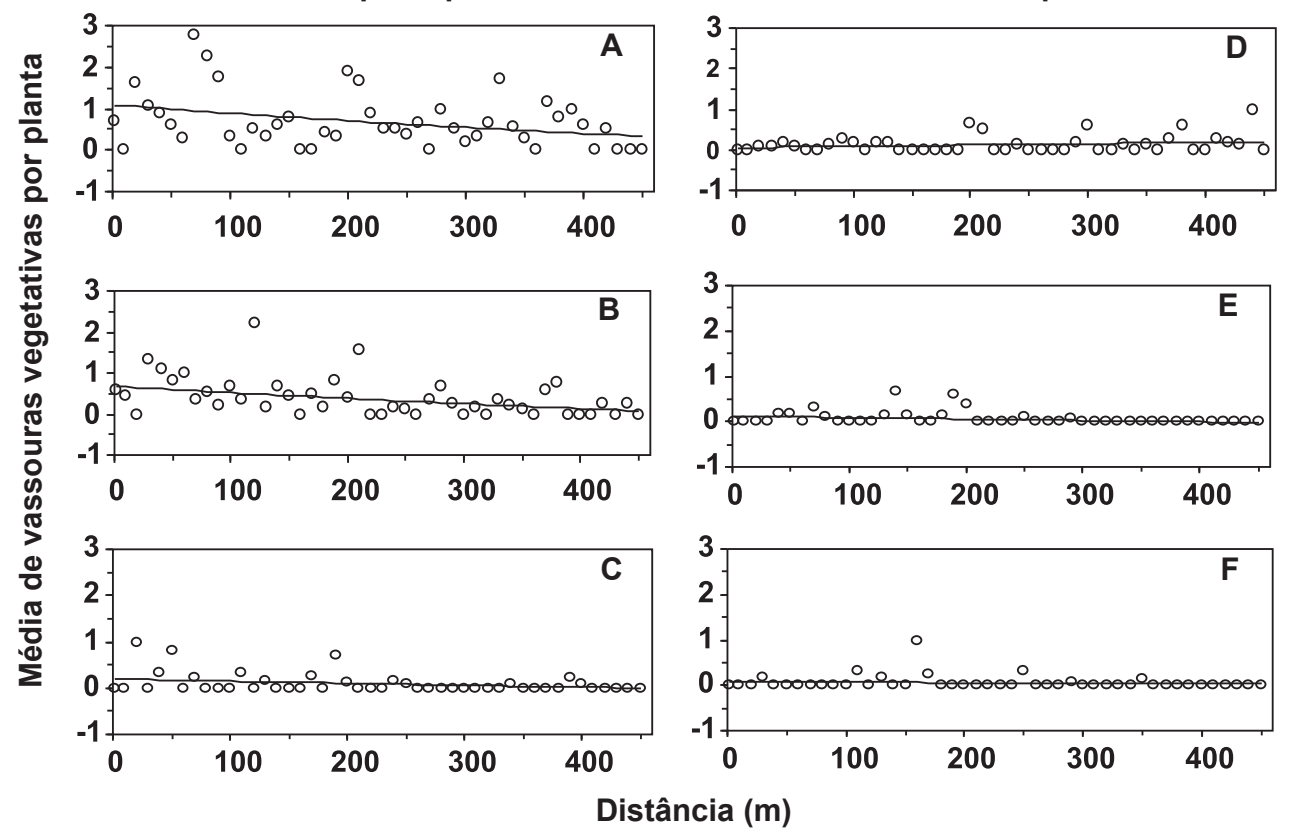

Safra temporã

FIG. 3 - Gradientes de incidência de vassoura-de-bruxa do cacaueiro, quantificados em vassouras vegetativas, em todos os genótipos. $\mathrm{Na}$ safra principal (setembro de 2001 a fevereiro de 2002), A. subárea 1 ; B. sub-área 2; C. sub-área 3. Na safra temporã (março a agosto de 2002); D. sub-área 1; E. sub-área 2; F. sub-área 3. Fazenda Novo Oriente, Uruçuca, BA.
"Crioulo" e 8,13 vassouras por planta em variedades híbridas. Almeida \& Andebrhan (1987) quantificaram 468 infecções (em ramos e almofadas florais) por planta em cacaueiros com 8 a 10 anos de idade. Rudgard (1987), ao investigar a produção de vassouras em plantas híbridas suscetíveis (Catongo X UF613), com aproximadamente 10 anos de idade, encontrou 184 vassouras vegetativas, no ano de 1984 , no Estado de Rondônia. Almeida et al. (1998) observaram incidência média de 289,5 vassouras por cacaueiro, antes da instalação do experimento, na Bahia, no ano de 1993.
Incidência em ramos e frutos. Baker et al. (1941) foram os primeiros a registrar diminuição do número de vassouras por planta com o aumento da distância a partir de uma área sem poda fitossanitária, que serviu como fonte de inóculo. No trabalho desses autores, a área experimental foi dividida em 36 parcelas de 16 plantas cada, com seis genótipos diferentes (ICS 1, 7, 16, 22, 45 e 53) e idade entre dois e três anos. Os genótipos apresentaram uma incidência média de aproximadamente 5,5 vassouras/planta e menor número de vassouras foi observado com o aumento da

TABELA 4 - Resultado das análises de regressão das contagens de frutos infectados com vassoura-de-bruxa em função da distância da fonte de inóculo, na safra principal e temporã, aplicando o modelo exponencial, em genótipos de cacaueiro

\begin{tabular}{|c|c|c|c|c|c|c|c|c|c|c|c|}
\hline \multirow{3}{*}{ Genótipo } & \multirow{3}{*}{$\begin{array}{l}\text { Sub- } \\
\text { área }\end{array}$} & \multicolumn{10}{|c|}{ Safra } \\
\hline & & \multicolumn{5}{|c|}{ Principal } & \multicolumn{5}{|c|}{ Temporã } \\
\hline & & $\begin{array}{c}\text { Inclinação } \\
\text { (b) }\end{array}$ & $\begin{array}{c}\text { Interseção } \\
(\ln \text { a) }\end{array}$ & $R^{2}$ & $\mathrm{~F}^{1}$ & & $\begin{array}{c}\text { Inclinação } \\
\text { (b) }\end{array}$ & $\begin{array}{c}\text { Interseção } \\
(\ln \text { a) }\end{array}$ & $R^{2}$ & $F^{1}$ & \\
\hline \multirow[t]{3}{*}{ Todos } & 1 & 0,0008 & 0,3085 & 0,095 & 4,61 & $*$ & $5.10^{-5}$ & 0,1051 & 0,002 & 0,07 & ns \\
\hline & 2 & 0,0004 & 0,3744 & 0,021 & 0,96 & ns & $-0,0006$ & 0,2727 & 0,198 & 10,84 & $* *$ \\
\hline & 3 & $-8.10^{-5}$ & 0,1616 & 0,003 & 0,14 & $\mathrm{~ns}$ & $-0,0005$ & 0,2177 & 0,125 & 6,28 & $*$ \\
\hline \multirow[t]{3}{*}{ NO-17 } & 1 & 0,0012 & 0,3125 & 0,068 & 0,59 & ns & $-3.10^{-5}$ & 0,0366 & 0,001 & 0,01 & ns \\
\hline & 2 & $-0,0014$ & 0,3466 & 0,375 & 3,00 & ns & 0,0014 & $-0,033$ & 0,094 & 0,52 & $\mathrm{~ns}$ \\
\hline & 3 & 0,0001 & 0,0645 & 0,003 & 0,03 & ns & $3.10^{-6}$ & 0,0908 & $2 \mathrm{E}-06$ & $2 \mathrm{E}-05$ & ns \\
\hline \multirow[t]{3}{*}{ NO-24 } & 1 & $-0,0021$ & 0,8858 & 0,298 & 5,09 & $*$ & $-0,0006$ & 0,2011 & 0,208 & 3,15 & ns \\
\hline & 2 & 0,0016 & 0,2414 & 0,246 & 3,91 & ns & $-0,0004$ & 0,2147 & 0,049 & 0,62 & ns \\
\hline & 3 & $-0,0053$ & 0,5766 & 0,159 & 1,14 & ns & $-0,0079$ & 0,8956 & 0,315 & 2,76 & ns \\
\hline \multirow[t]{3}{*}{ NO-34 } & 1 & 0,0013 & 0,0427 & 0,161 & 5,94 & $*$ & $-0,0001$ & 0,0805 & 0,019 & 0,59 & ns \\
\hline & 2 & $-0,0012$ & 0,3643 & 0,099 & 1,53 & ns & $-0,0011$ & 0,2091 & 0,284 & 5,56 & $*$ \\
\hline & 3 & 0,0012 & $-0,1528$ & 0,477 & 13,67 & $* *$ & 0,00 & 0,00 & - & - & \\
\hline \multirow[t]{3}{*}{ NO-42 } & 1 & $-0,0003$ & 0,3652 & 0,003 & 0,03 & ns & 0,0002 & 0,0299 & 0,016 & 0,18 & ns \\
\hline & 2 & 0,001 & 0,0248 & 0,151 & 4,62 & $*$ & $-0,0004$ & 0,272 & 0,028 & 0,73 & $\mathrm{~ns}$ \\
\hline & 3 & $-0,0002$ & 0,0286 & 0,178 & 2,37 & ns & $-0,0019$ & 0,2615 & 0,321 & 5,21 & $*$ \\
\hline
\end{tabular}

$1 *, * *$ significante a $5 \%$ e a $1 \%$ de probabilidade, respectivamente; ns, não significativo. 
Safra principal

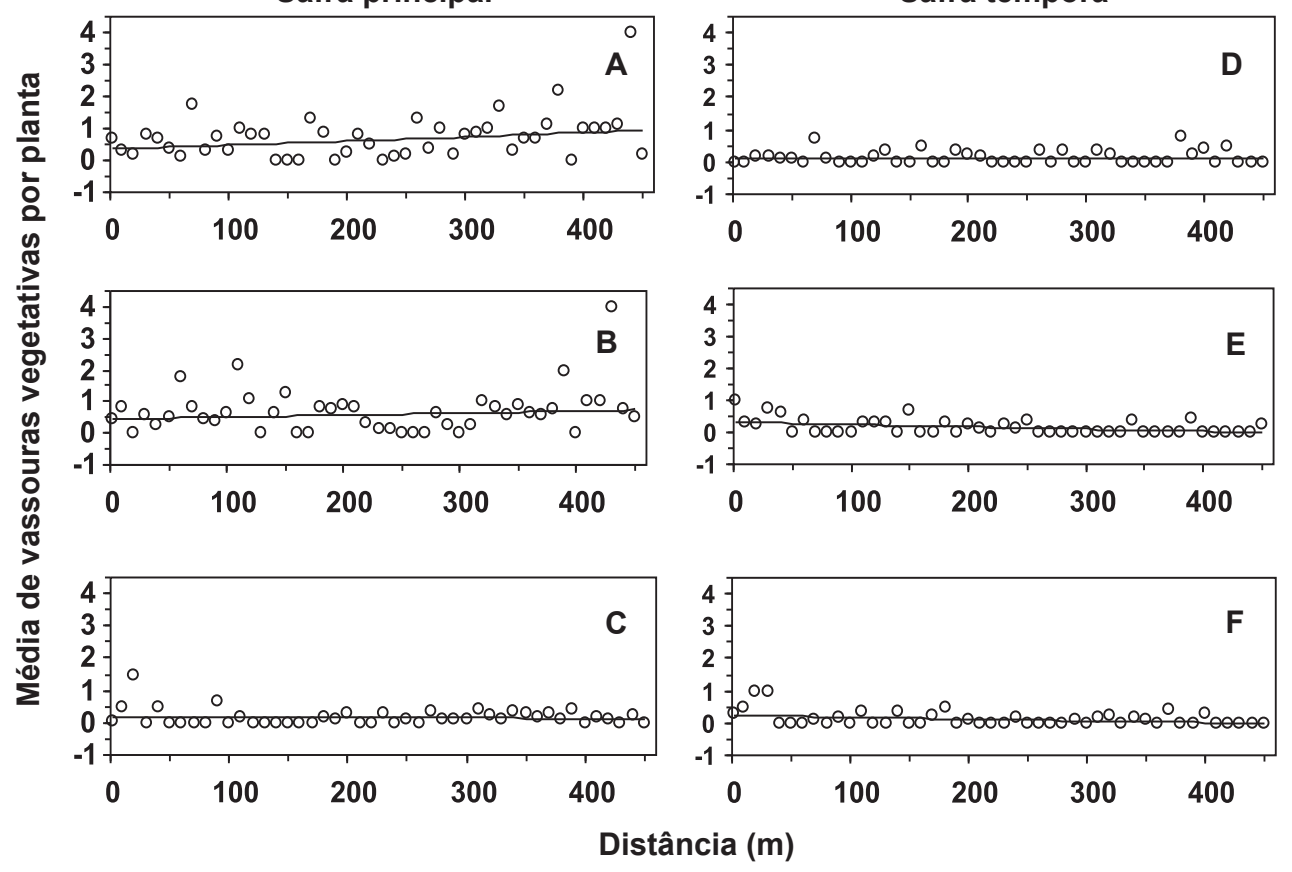

FIG. 4 - Gradientes de incidência de vassoura-de-bruxa do cacaueiro em frutos com vassoura, em todos os genótipos. $\mathrm{Na}$ safra principal (setembro de 2001 a fevereiro de 2002), A. sub-área $1 ; \mathbf{B}$. sub-área $2 ; \mathbf{C}$. sub-área 3. Na safra temporã (março a agosto de 2002); D. sub-área 1; E. sub-área 2; F. subárea 3. Fazenda Novo Oriente, Uruçuca, BA. distância da área adjacente com alta severidade da doença. Os autores afirmaram que a influência da área adjacente sem poda fitossanitária foi mais acentuada até cerca de $90 \mathrm{~m}$.

Embora no presente experimento, realizado na plantação da fazenda Novo Oriente, também tenha sido avaliada uma mistura de genótipos com dois e três anos de idade, a média de vassouras produzidas por planta foi muito menor (0,61 vassouras/planta) que a incidência observada por Baker et al. (1941), provavelmente em função de uma maior resistência genética.

Os primeiros trabalhos que tiveram a preocupação de analisar o gradiente de incidência da doença em almofadas florais e frutos, além de vassouras vegetativas, foram conduzidos por Maddison et al. (1993), com protocolos semelhantes em dois locais no Brasil, dois na Colômbia, um no Equador e um na Venezuela. Nesses trabalhos foram delimitadas, dentro da mesma área, dez linhas como fonte de inóculo e 35 linhas para a quantificação do gradiente. Em quatro locais as análises de variância em vassouras vegetativas foram significativas, com valores da inclinação variando de $-0,1022$ a -0,0174 e coeficientes de determinação variando de 0,44 a 0,82. Em frutos, três locais apresentaram análises de variância significativas, variando a inclinação da reta de $-0,0009$ a -0,0089 e os coeficientes de determinação de 0,12 a 0,49. Comparando-se os resultados de Maddison et al. (1993) aos do presente trabalho, pode-se observar que este apresenta valores de inclinação do gradiente menores, tanto em vassouras vegetativas como em frutos com vassoura. A metodologia aqui utilizada para a detecção do gradiente objetivou constatar o que realmente acontece no campo, sem quaisquer manipulações que poderiam favorecer o patógeno, diferentemente do que é feito quando se objetiva analisar o gradiente de doença em mudas. Aragundi et al. (1987) e Rudgard (1987) obtiveram gradientes com inclinações maiores do que neste estudo com o uso de mudas suscetíveis à doença.

A inexistência de evidência de um gradiente de doença neste trabalho, aliada à detecção da doença em toda a área experimental, sugere que basidiósporos do patógeno encontram-se disseminados de forma generalizada no sudeste da Bahia, o que dificulta e pode até inviabilizar o controle da doença se a mesma for tratada apenas com podas fitossanitárias em propriedades isoladas, haja vista que há extensas e contínuas áreas de cacaueiros nessa região.

Todas as vassouras produzidas na área experimental foram retiradas, evitando-se, portanto, a possibilidade do inóculo ter sido produzido dentro da área experimental. Os ramos e frutos que se apresentaram doentes foram infectados, com grande probabilidade, a partir de inóculo oriundo de área externa ao experimento. Evans \& Solorzano (1982) observaram mudas infectadas com vassoura-de-bruxa em uma área isolada distante $800 \mathrm{~m}$ de outras plantações de cacau, sugerindo a capacidade de disseminação do inóculo aéreo a longas distâncias.

Em Palma Cháves, Equador, houve registro de 8\% de frutos doentes e de 40 vassouras por árvore mesmo após uma cuidadosa retirada das vassouras de toda a plantação (Maddison et al., 1993). Os autores presumiram que a maior parte dessas infecções foi devida a inóculo oriundo de outras plantações. Segundo Tollenaar (1959), não há evidências que a remoção de vassouras implique na redução da doença em frutos, pois incidências de até $80 \%$ foram constatadas num período chuvoso.

Maddison et al. (1993), ao comparar gradientes de doença observados em três tecidos diferentes (almofadas florais, ramos e frutos), revelaram que os mesmos diferiram 
para um mesmo local. Em conseqüência, afirmam que uma distância que proporciona baixa infecção em almofadas florais poderia não ser suficiente para reduzir igualmente a incidência em ramos e frutos. As causas para que haja essa diferença não são conhecidas. Os mesmos autores especulam que tal fato pode ser resultado de diferenças no período de suscetibilidade dos diferentes tecidos.

Os ramos possuem um período de suscetibilidade mais curto, sendo que as gemas ativas são bastante suscetíveis e à medida que a brotação se desenvolve a infecção se torna mais difícil, não ocorrendo a infecção em folhas maduras (Baker \& Crowdy, 1943). Frias et al. (1991) observaram que em brotações no estádio F-2 (folhas maiores que $1,5 \mathrm{~cm}$ de comprimento) há pronunciada diminuição na orientação do tubo germinativo dos basidiósporos, quando comparada com brotações mais jovens. Por outro lado, infecção de gemas dormentes já foi obtida com sucesso (Bastos, 1994). O período de suscetibilidade em frutos é de aproximadamente 100 dias (Andebrhan, 1981 e 1985).

Com a ausência de gradiente de doença, não foi possível determinar neste experimento uma distância máxima de disseminação do patógeno ou uma distância segura entre novos plantios e áreas abandonadas. A maior resistência genética dos clones testados propiciou baixa incidência da doença, marcadamente na sub-área submetida ao controle cultural e químico, evidenciando a eficiência do manejo integrado para a vassoura-de-bruxa nas condições do sudeste baiano.

\section{AGRADECIMENTOS}

Ao Conselho Nacional de Desenvolvimento Científico e Tecnológico (CNPq) pela concessão de bolsa de estudos durante o segundo ano do curso de mestrado do primeiro autor e ao Sr. Paulo Torres, Uruçuca BA, por autorizar a realização dos trabalhos em sua propriedade.

\section{REFERÊNCIAS BIBLIOGRÁFICAS}

ALMEIDA, L.C. \& ANDEBRHAN, T. Recuperação de plantações de cacau com alta incidência de vassoura-de-bruxa na Amazônia brasileira. Proceedings, 10 ${ }^{\mathrm{a}}$ Conferência Internacional de Pesquisas em Cacau, Santo Domingo, 1987. pp. 337-339.

ALMEIDA, L.C.C., NIELLA, G.R. \& BEZERRA, J.L. Efeito de remoções de partes doentes do cacaueiro associadas a intervalos de aplicação de óxido cuproso no controle da vassoura-de-bruxa na Bahia. Agrotrópica 10:95-102. 1998.

ALVIM, P.T. Cacao. In: Alvim, P.T. \& Kozlowski, T.T. (Eds.) Ecophysiology of Tropical Crops. New York NY. Academic Press. 1977. pp. 279-313.

ANDEBRHAN, T. Relação entre a idade do fruto do cacaueiro e suscetibilidade a Crinipellis perniciosa. In: Comissão Executiva do Plano da Lavoura Cacaueira, Departamento Especial da Amazônia. Informe Técnico. 1981. pp. 315-317.
ANDEBRHAN, T. Studies on the epidemiology and control of witches' broom disease of cacao in the Brazilian Amazon. Proceedings, $9^{\text {th }}$ International Cocoa Research Conference, Lome (Togo), 1985. pp. 395-402.

ANDEBRHAN, T. \& ALMEIDA, L.C. Aspectos fenológicos da resistência do cacaueiro a C. perniciosa. In: Comissão Executiva do Plano da Lavoura Cacaueira, Departamento Especial da Amazônia. Informe Técnico. 1985. pp. 61-62.

ARAGUNDI, J., FRIAS, G., SOLORZANO, G., SCHIMIDT, R. \& PURDY, L.H. Estudios sobre gradiente de infeccion y dispersion de la escoba de bruja del cacao en el Ecuador. Proceedings, $10^{\mathrm{a}}$ Conferencia Internacional de Investigación en Cacao, Santo Domingo, 1987. pp. 375-379.

BASTOS, C.N. Capacidade de Crinipellis perniciosa produzir basidiósporos viáveis em vassouras com três anos de idade e de infectar tecidos do cacaueiro com gemas dormentes. Fitopatologia Brasileira 19:585-587. 1994.

BAKER, R.E.D. \& CROWDY, S.H. Studies in the witches' broom disease of cocoa caused by Marasmius perniciosus Stahel.: Introduction, symptons and etiology. Port-of-Spain. ICTA. 1943. (Memoir 7)

BAKER, R.E.D., CROWDY, S.H. \& THOROLD, C.A. Witches' broom disease investigations. I. Seasonal variations in the intensity of infections and their effect on control measures. Tropical Agriculture (Trinidad) 18:107-116. 1941.

BERGAMIN FILHO, A. \& AMORIM, L. Doenças com período de incubação variável em função da fenologia do hospedeiro. Fitopatologia Brasileira 27:561-565. 2002.

BERGAMIN FILHO, A., HAU, B., AMORIM, L. \& LARANJEIRA, F.F. Análise espacial de epidemias. Revisão Anual de Patologia de Plantas 10:155-218. 2002.

CARZOLA, I.M., AIDAR, I. \& MILDE, L.C.E. Perfis do lançamento foliar, da floração, da bilração e de estágios do fruto do cacaueiro no Estado da Bahia, no período 1977/88. Ilhéus. CEPLAC. 1989.

CIFUENTES, C., MAYORGA, M., PRIETO, E., RONDON, G. \& TOVAR, G. Estudio cuantitativo de la produccion de escobas en plantas de cacao, afectadas por Crinipellis perniciosa (Stahel) Singer y su significado en el manejo de la enfermidad. Proceedings, 8a Conferencia Internacional de Investigación en Cacao, Cartagena, Colombia, 1982. pp. 407-413.

COMPANHIA DAS DOCAS DO ESTADO DA BAHIA, 2002. Apresenta, em estatísticas, os principais produtos movimentados. $<$ http://www.codeba.com.br/portoilheus $>$. (15 nov. 2002)

EVANS, H.C. \& SOLORZANO, G.R. Witches' broom disease: wrong experiment rigth results. Proceedings, 8 ${ }^{\mathrm{a}}$ Conferencia Internacional de Investigación en Cacao, Cartagena, Colombia, 1982. pp. 415-418.

FAO. Prodution Yearbook, v.54, 2000. Rome, 2002.

FRIAS, G.A., PURDY, L.H. \& SCHIMIDT, R.A. Infection biology of Crinipellis perniciosa on vegetative flushes of cacao. Plant Disease 75:552-556. 1991.

LUZ, E.D.M.N., BEZERRA, J.L., OLIVEIRA, M.L. \& RESENDE, M.L.V. Doenças do cacaueiro. In: Vale, F.X.R. \& Zambolim, L. (Eds.) Controle de Doenças de Plantas: grandes culturas. Viçosa. UFV. Imprensa Universitária. 1997. pp. 611-655.

MADDISON, A.C., ANDEBRHAN, T., ARANZAZU, F. \& 
SILVA-ACUÑA, R. Comparative phytosanitation studies. In: Rudgard, S.A., Maddison, A.C. \& Andebrhan, T. (Eds.). Disease Management in Cocoa: Comparative Epidemiology of Witches' Broom. London. Chapman \& Hall. 1993. pp. 165-188.

PEREIRA, J.L., RAM, A., FIGUEIREDO, J.M. \& ALMEIDA, L.C.C. First occurrence of witches' broom disease in the principal cooca-growing region of Brasil. Tropical Agriculture (Trinidad) 67:188-189. 1990.

PURDY, L.H. \& SCHMIDT, R.A. Status of cacao witches' broom: biology, epidemiology, and management. Annual Review of Phytopathology 34:573-594. 1996.

ROSA, I.S. Enxertia do cacaueiro. Ilhéus. CEPLAC/SUBES/ CEPEC. 1998.

RUDGARD, S.A. Interpreting the epidemiology of cocoa witches' broom for better disease management in Rondonia, Brazil. Cocoa
Growers' Bulletin 38:28-38. 1987.

RUDGARD, S.A., MADDISON, A.C. \& ANDEBRHAN, T. Disease Management in Cocoa: Comparative Epidemiology of Witches' Broom. London. Chapman \& Hall. 1993.

SANTOS FILHO, L.P., FREIRE, E.S. \& CARZOLA, I.M. Estimativas de perdas de produção de cacau causadas por vassourade-bruxa (Crinipellis perniciosa (Stahel) Singer) na Bahia. Agrotrópica 10:127-130. 1998.

TOLLENAAR, C.A. Increase cocoa production by foliar copper applications as an effect additional to witches'broom disease control. Tropical Agriculture (Trinidad) 36:177-188. 1959.

TREVIZAN, S.D.P. Mudanças no sul da Bahia associadas a vassoura-de-bruxa do cacau. Proceedings, $8^{\mathbf{a}}$ Conferência Internacional de Pesquisas em Cacau, Salvador, BA. 1996. pp. 1109-1116. 